\title{
The Application of Integrated Assisted History Matching and Embedded Discrete Fracture Model Workflow for Well Spacing Optimization in Shale Gas Reservoirs with Complex Natural Fractures
}

\author{
Qiwei Li, ${ }^{1}$ Jianfa Wu, ${ }^{2}$ Cheng Chang, ${ }^{2}$ Hongzhi Yang, ${ }^{2}$ Chuxi Liu, ${ }^{1}$ Wei Yu ${ }^{1},{ }^{1,3}$ \\ Kamy Sepehrnoori, ${ }^{1}$ and Jijun Miao ${ }^{3}$ \\ ${ }^{1}$ Hildebrand Department of Petroleum and Geosystems Engineering, The University of Texas at Austin, Austin, Texas 78712, USA \\ ${ }^{2}$ Petrochina Southwest Oil \& Gas Field Company, Chengdu 610017, China \\ ${ }^{3}$ Sim Tech LLC, Houston, Texas 77494, USA \\ Correspondence should be addressed to Wei Yu; yuwei127@gmail.com
}

Received 9 December 2020; Revised 26 January 2021; Accepted 24 February 2021; Published 18 March 2021

Academic Editor: Jinze Xu

Copyright (c) 2021 Qiwei Li et al. This is an open access article distributed under the Creative Commons Attribution License, which permits unrestricted use, distribution, and reproduction in any medium, provided the original work is properly cited.

\begin{abstract}
An appropriate well spacing plan is critical for the economic development of shale gas reservoirs. The biggest challenge for well spacing optimization is interpreting the subsurface uncertainties associated with hydraulic and natural fractures. Another challenge is the existence of complex natural fractures. This work applied an integrated well spacing optimization workflow in shale gas reservoirs of the Sichuan Basin in China with both hydraulic and natural fractures. The workflow consists of five components: data preparation, reservoir simulation, estimated ultimate recovery (EUR) analysis, economic calculation, and well spacing optimization. Firstly, the multiple realizations of thirteen uncertain parameters of matrix and fractures, including matrix permeability and porosity, three relative permeability parameters, hydraulic fracture height, half-length, width, conductivity, water saturation, and natural fracture number, length, and conductivity, were captured by the assisted history matching (AHM). The fractures were modeled by the embedded discrete fracture model (EDFM) accurately and efficiently. Then, 84 AHM solutions combining with five well spacing scenarios from $517 \mathrm{ft}$ to $1550 \mathrm{ft}$ would generate 420 simulation cases. After reservoir simulation of these 420 cases, we forecasted the long-term gas production for each well spacing scenario. Gas EUR degradation and well interference would imply the critical well spacing. The net present value (NPV) for all scenarios would be calculated and trained by $K$-nearest neighbors $(\mathrm{KNN})$ proxy to better understand the relationship between well spacing and NPV. In this study, the optimum well spacing was determined as $793 \mathrm{ft}$, corresponding with a maximum NPV of 18 million USD, with the contribution of hydraulic fractures and natural fractures.
\end{abstract}

\section{Introduction}

There is no doubt that the development of unconventional reservoirs has changed the oil and gas industry. However, many challenges, such as heterogeneity, nanopore, proppant distribution, multiphase flow, and complex fractures, have existed in unconventional reservoirs [1-3]. Reservoir simulation is a rigorous method applied in unconventional reservoirs. Among the worldwide unconventional resources, shale gas and oil are the main components. Optimum well spacing is one of the key parameters for shale reservoir development. It is essential to find a well spacing that can balance the recovery and economics. Many studies have focused on this area both numerically and analytically $[4,5]$. Some of them have investigated the controlling factors for the well spacing determination, such as fracture half-length, reservoir permeability, rock properties, and natural fractures [6-8]. However, due to shale reservoirs' complexity, it is still challenging to quantify the subsurface uncertainty-associated hydraulic and natural fractures $[9,10]$. Several methods, 


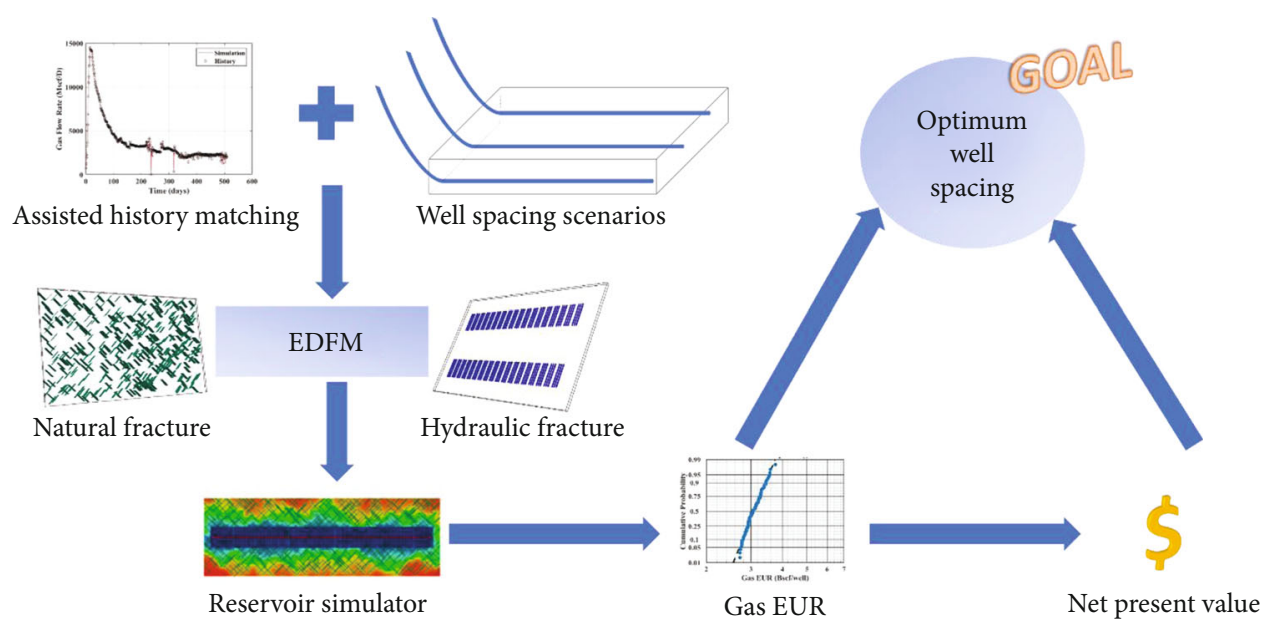

FIGURE 1: An integrated AHM and EDFM workflow for well spacing optimization in shale gas reservoirs with complex natural fractures.

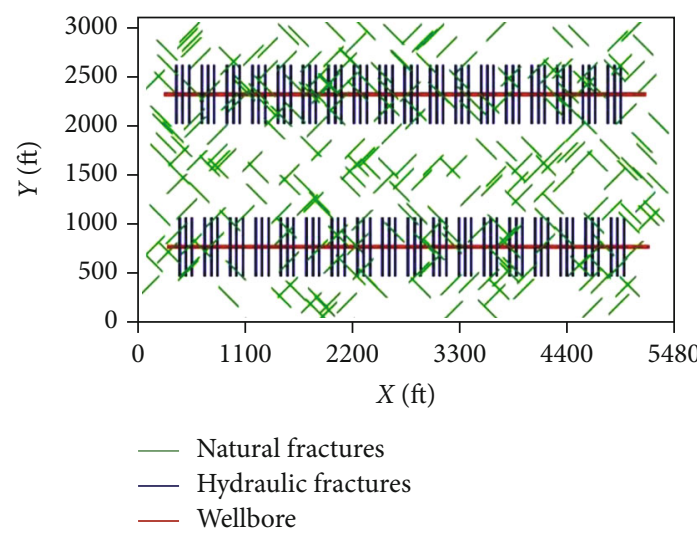

(a)

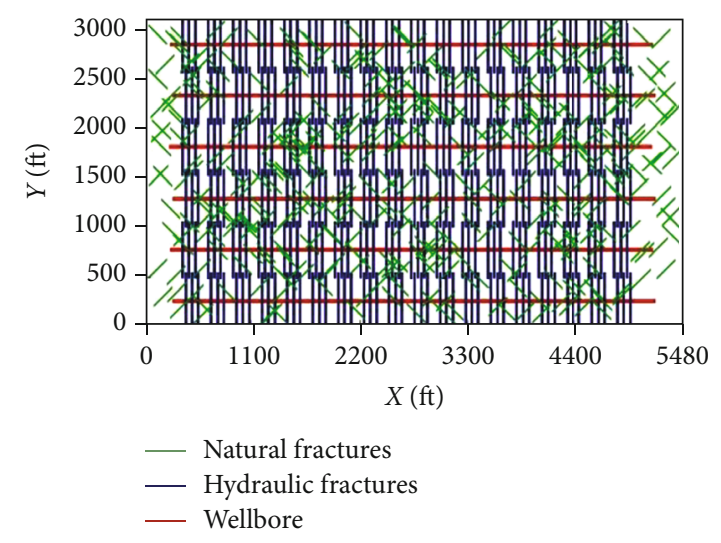

(b)

FIGURE 2: A field-scale reservoir model for five well spacing schemes used in this study: (a) a 2-well placement scenario with a spacing of $1550 \mathrm{ft}$ and (b) a 6-well placement scenario with a spacing of $517 \mathrm{ft}$.

including the microseismic method, well test method, and rate-transient analysis (RTA) method, have applied to capture the uncertain parameters [11-14]. Nevertheless, the high data requirement of these methods makes it not easy to be performed in new wells.

Another method widely used in calibrating uncertainties is history matching, which is an efficient and inexpensive approach. Many authors have performed single history matching to obtain one solution of shale reservoir and fractures [15-19]. However, the nonuniqueness of history matching should be considered. Therefore, multiple history matching was applied. Cao et al. [20] determined the optimal well spacing for Delaware Basin by multiple history matching. What is more, they did not take the uncertainty of natural fractures into account, which is another challenge for the well spacing optimization in shale reservoirs.

Several researchers have investigated that natural fractures could impact the fracture's propagation during hydraulic fracturing by microseismic event patterns and complex fracture propagation models [21-24]. [2] modeled the complex natural fractures by the embedded discrete fracture model (EDFM), a modeling method with accuracy and efficiency. They indicated that the two-set natural fractures could increase the gas recovery by $23.2 \%$ after 30 years.

In this study, we applied an integrated AHM and EDFM workflow for well spacing optimization in shale gas reservoirs of Sichuan Basin in China with complex natural fractures. The hydraulic fractures and natural fractures were modeled by the EDFM method [2]. According to 84 AHM solutions for a shale gas well in this reservoir, the multiple realizations of thirteen uncertain matrix and fracture parameters can be calibrated. It is worth pointing out that the uncertain parameters of natural fractures include the number, the length, and the conductivity of natural fractures. We also considered three uncertainties about relative permeability. Then, we compared the gas EUR in the long-term from the reservoir simulation results for five well spacing scenarios associated with these 84 solutions. The well spacing scenarios are distributed from $517 \mathrm{ft}$ to $1550 \mathrm{ft}$, corresponding to 6 wells to 2 wells. The critical well spacing can be determined by analyzing the gas EUR degradation to minimize well interference. Then net present values (NPVs) of all cases can be 
evaluated and predicted by $K$-nearest neighbors (KNN) proxy to identify the optimum well spacing for this shale reservoir with natural fractures.

\section{Well Spacing Optimization Workflow}

The integrated well spacing optimization workflow consists of five components: data preparation, reservoir simulation, EUR analysis, economic calculation, and well spacing optimization. The framework is shown in Figure 1. First, we need to prepare the input data for the reservoir simulation. There are two main things we need to decide. One is which uncertain parameters of matrix and fractures are essential to the shale gas reservoir. According to the short-term production data, we apply AHM to calibrate the distribution of these uncertain parameters and screen the results of AHM solutions with the lowest global error. Another is to design the minimal and maximum numbers of well placed into the reservoir to figure out the optimum well spacing. If the well spacing is too small, the well interference will reduce the gas production per well; if the well spacing is too large, the recovery may not satisfy. Therefore, it is essential to determine the range of well spacing and design several well spacing scenarios. The input of simulation cases can then be generated by integrating the AHM solutions and well spacing scenarios and modeled by EDFM considering hydraulic and natural fractures.

Subsequently, the reservoir simulation is performed for all cases to forecast the long-term gas production. Cumulative gas production and gas EUR of each case can be calculated and analyzed in a lognormal probability plot. By comparing gas EUR degradation, the influence of well interference is observed, and the corresponding critical well spacing minimizing well interference can be obtained. Next, we evaluate the NPV for all the cases and plotted them into a boxplot. The equation of NPV is discussed in our previous work [25]. The P50 NPV for each well spacing scenario can be obtained directly. Besides, to better understand the relationship between NPV and well spacing, we predict the NPV for more well spacing using the KNN proxy method. The calculated NPV is considered as a predictor, and the corresponding well spacing is added into the prediction features. Finally, we can identify the optimum well spacing, which leads to the maximum NPV.

\section{Field Application}

3.1. Reservoir Model. Our integrated AHM and EDFM workflow is applied to a shale gas reservoir in the Sichuan Basin in China with complex natural fractures to determine the optimum well spacing for hydraulic-fractured wells. First, it is essential to build a field-scale model to represent the shale gas reservoir. The schemes of the model are shown in Figure 2. The model is $5840 \mathrm{ft}$ long in the $x$-direction and $3100 \mathrm{ft}$ long in the $y$-direction. The thickness is $65 \mathrm{ft}$ in the $z$-direction. The red lines are the horizontal wells with a constant length of $4921 \mathrm{ft}$. We set 2 to 6 wells in the model to illustrate the different well spacings. Figure 2(a) represents the well spacing of $1550 \mathrm{ft}$ at two wells per section, while
TABLE 1: Summary of reservoir and fracture properties used in this study.

\begin{tabular}{lcc}
\hline Reservoir description & Value & Unit \\
\hline Model dimension $(x \times y \times z)$ & $5480 \times 3100 \times 65$ & $\mathrm{ft}$ \\
Number of grid blocks $(x \times y \times z)$ & $137 \times 31 \times 1$ & - \\
Grid block dimension $(x \times y \times z)$ & $40 \times 100 \times 65$ & $\mathrm{ft}$ \\
Initial reservoir pressure & 8847.3 & $\mathrm{psi}$ \\
Reservoir temperature & 215 & ${ }^{\circ} \mathrm{F}$ \\
Residual water saturation & $20 \%$ & - \\
Residual gas saturation & $10 \%$ & - \\
Matrix water saturation & $39 \%$ & - \\
Total compressibility & $3 \times 10^{-6}$ & $\mathrm{psi}{ }^{-1}$ \\
Reservoir depth & 10499 & $\mathrm{ft}$ \\
Well length & 4921 & $\mathrm{ft}$ \\
Number of stages & 18 & - \\
Stage spacing & 145 & $\mathrm{ft}$ \\
Clusters per stage & 3 & - \\
Cluster spacing & 67 & $\mathrm{ft}$ \\
Number of natural fracture set & 2 & - \\
Natural fracture height & 65 & $\mathrm{ft}$ \\
Natural fracture theta & 90.1 & $\mathrm{Degree}$ \\
Natural fracture dip angle & 20 & $\mathrm{ft}$ \\
Natural fracture width & & Year \\
Total simulated time & $45 ; \mathrm{NF} 2135$ & \\
\hline
\end{tabular}

TABLE 2: Summary of ranges of 13 uncertain parameters used in this study [26].

\begin{tabular}{lccc}
\hline Uncertain parameters & Unit & Min value & Max value \\
\hline Matrix permeability & $\mathrm{md}$ & 0.00001 & 0.0001 \\
Fracture height & $\mathrm{ft}$ & 25 & 65 \\
Fracture half-length & $\mathrm{ft}$ & 200 & 780 \\
Fracture conductivity & $\mathrm{md}-\mathrm{ft}$ & 10 & 200 \\
Fracture water saturation & - & 0.5 & 0.9 \\
Fracture width & $\mathrm{ft}$ & 0.1 & 4 \\
Porosity & - & 0.038 & 0.083 \\
Exponent of krg & - & 1 & 4 \\
Endpoint of krw & - & 0.5 & 1 \\
Exponent of krw & - & 1 & 4 \\
Number of natural fractures & - & 200 & 1200 \\
Natural fracture length & $\mathrm{ft}$ & 100 & 500 \\
Natural fracture conductivity & $\mathrm{md}-\mathrm{ft}$ & 1 & 10 \\
\hline
\end{tabular}

Figure 2(b) shows the well spacing of $517 \mathrm{ft}$ at six wells per section. The blue lines distributed in the wells represent the 54 hydraulic fractures. They were separated into 18 stages, which are $145 \mathrm{ft}$ away from each other. And each stage contains 3 clusters with cluster spacing of $67 \mathrm{ft}$. The green lines are the natural fractures distributed at $45^{\circ}$ or $135^{\circ}$. Although there are other degrees of fracture growth azimuth existing, 


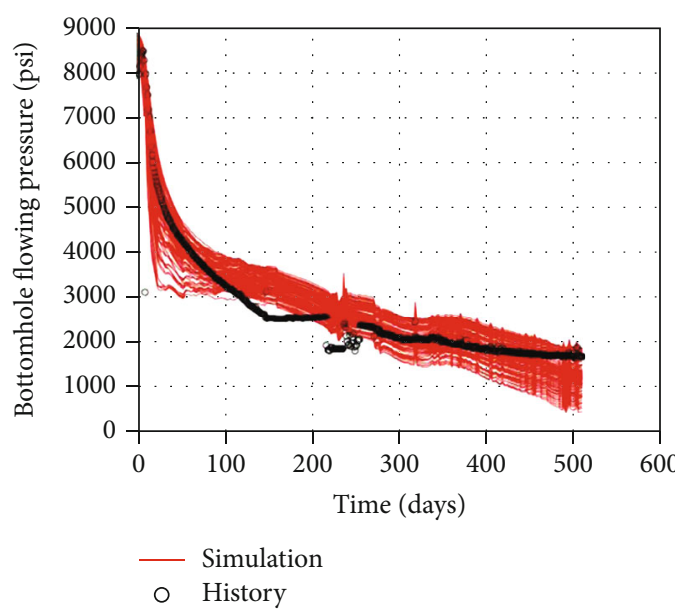

(a)

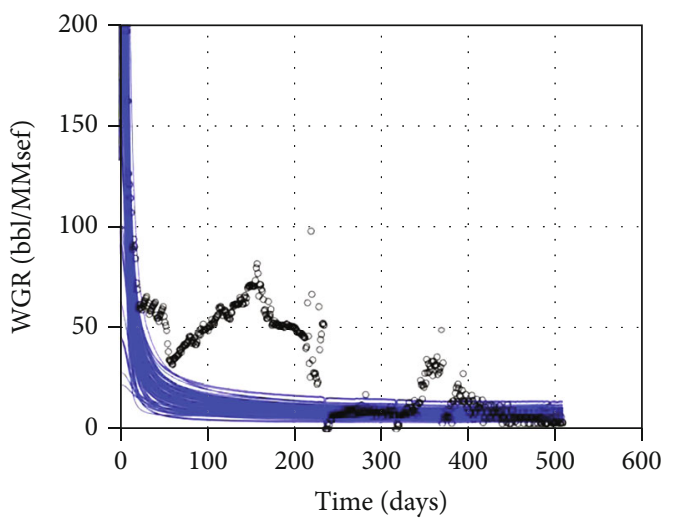

(c)



(b)

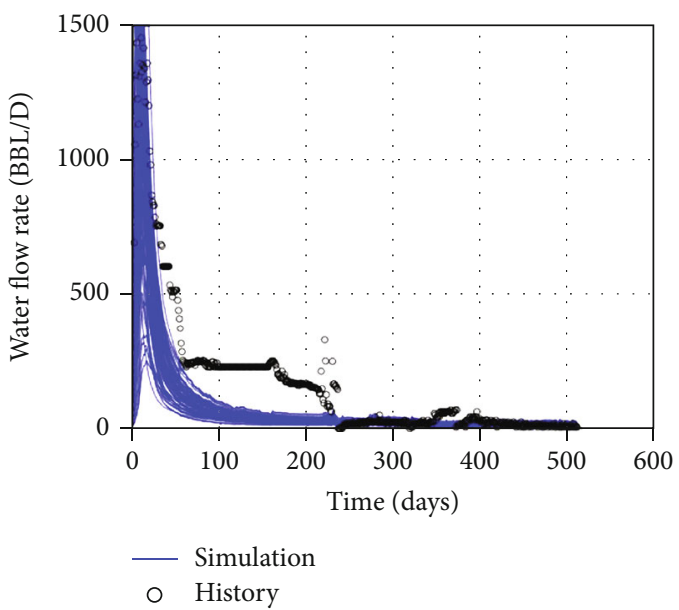

(d)

FiguRe 3: Comparison between 84 history matching solutions and field data [26]: (a) bottomhole pressure, (b) gas flow rate, (c) water-gas ratio, and (d) water flow rate.

we would only consider the ideal condition to simplify the method. One of the biggest reasons is lacking fracture diagnostic data. In this study, we assume the natural fractures have a constant height of $65 \mathrm{ft}$ and a width of $0.1 \mathrm{ft}$. And the dip angle of natural fractures is $90^{\circ}$. All fractures were modeled by EDFM. It is worth noting that the model is ideal, and the heterogeneity of the reservoir is not considered. Other properties of our reservoir model are listed in Table 1.

After demonstrating all the certain parameters, we need to calibrate the uncertain parameters of matrix and fractures for the shale gas reservoirs by history matching. The first step is to determine the critical parameters and their range based on prior expert experience. This study chose 13 parameters as uncertainties: matrix permeability, porosity, exponent of relative permeability for gas, exponent, and endpoint of relative permeability for water, hydraulic fracture height, half-length, conductivity, water saturation, and width, natural fracture number, length, and conductivity. These three parameters of natural fractures reflect the ability of fluid transport within the complex natural fractures. We limited the number of natural fractures from 200 to 1200 in this reservoir. Moreover, the natural fracture length is between $100 \mathrm{ft}$ to $500 \mathrm{ft}$, while the hydraulic fracture half-length is between $200 \mathrm{ft}$ and $780 \mathrm{ft}$. Other parameters' ranges are listed in Table 2. The assisted history matching was then performed to capture the multiple realizations of these parameters. Details of AHM workflow are discussed Tripopoom et al. [26]. For this reservoir, there are a total 84 assisted history solutions. Figures 3(a)-3(d) show the AHM results compared with short-term production data [26]. It is observed that the bottomehole pressure (BHP) and gas flow rate can match with the field production data properly. The water flow rate and water-gas ratio (WGR) match the production data overall, except for 50 days to 250 days, but we can find the water flow rate from production data during this period changes without the similar trend with BHP, which can be ignored for the overall results. Therefore, the history matching solutions are accurate enough for the following well spacing optimization.

The multiple realizations of uncertain parameters from AHM solutions are shown in Figure 4. Figures 4(a)-4(m) represent the posterior distribution of matrix permeability, 


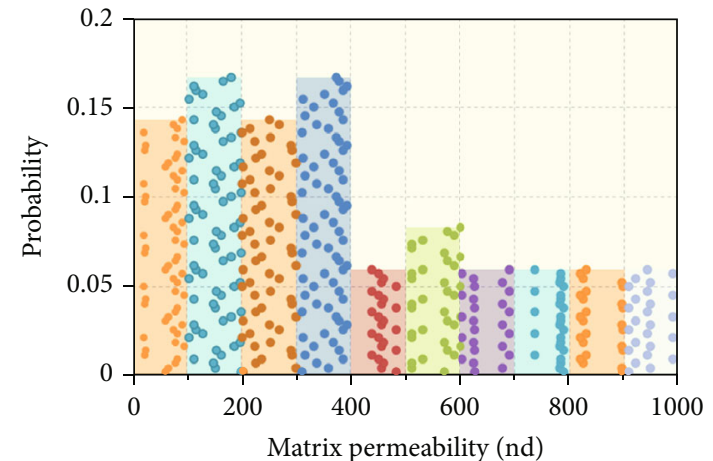

(a)

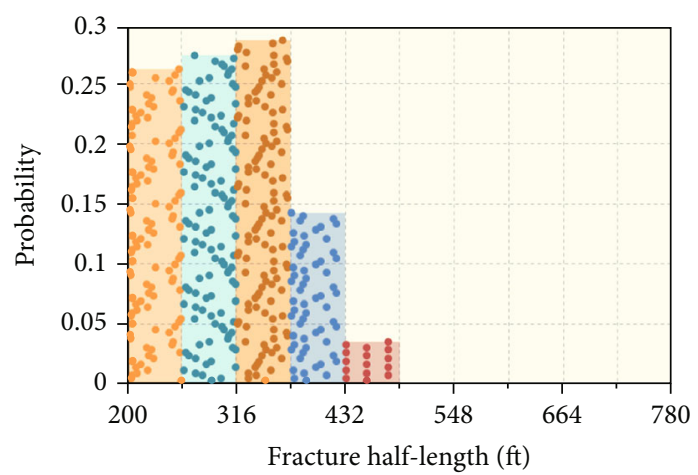

(c)

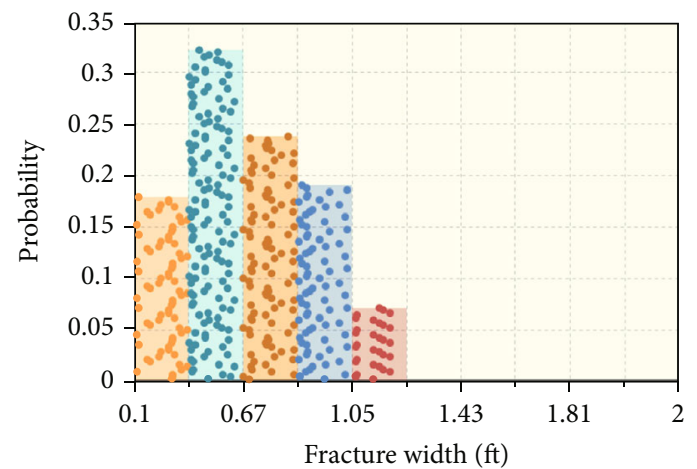

(e)

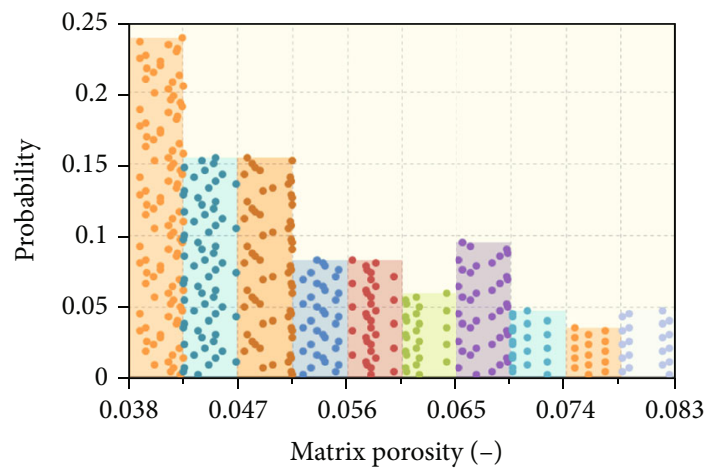

(g)

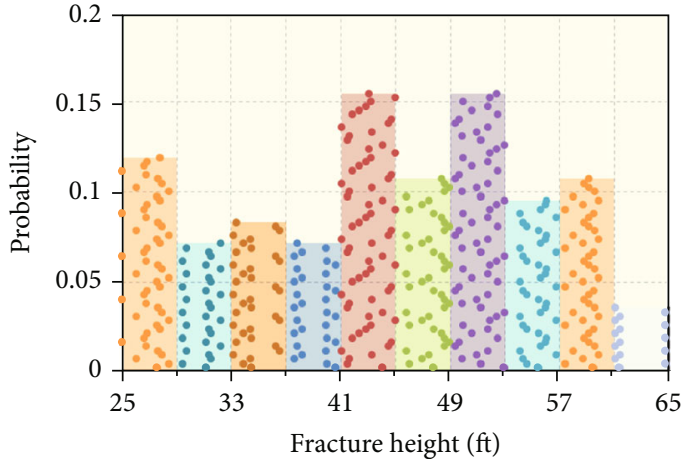

(b)

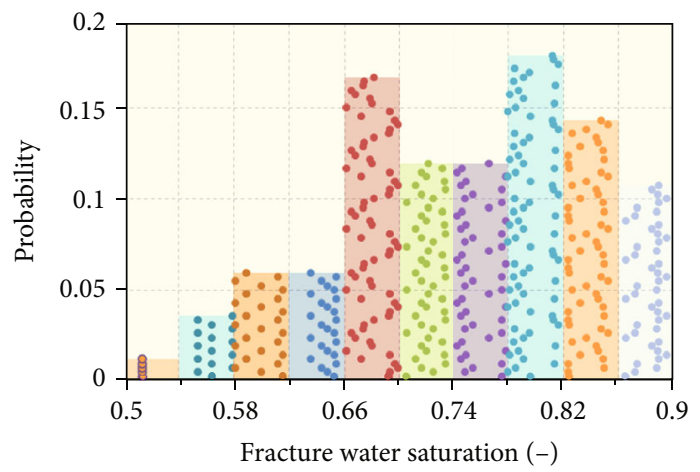

(d)

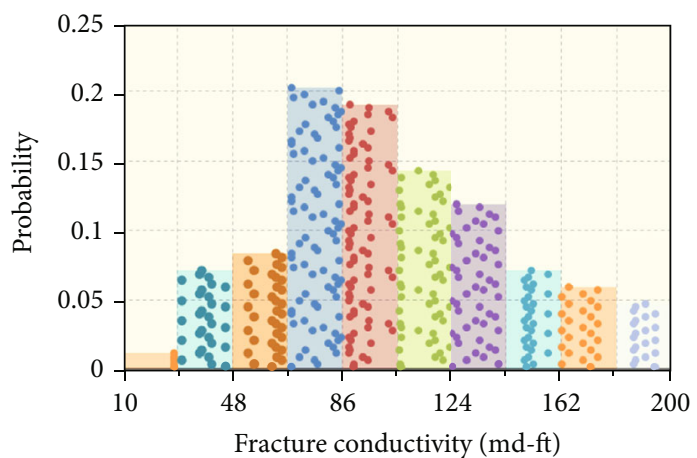

(f)

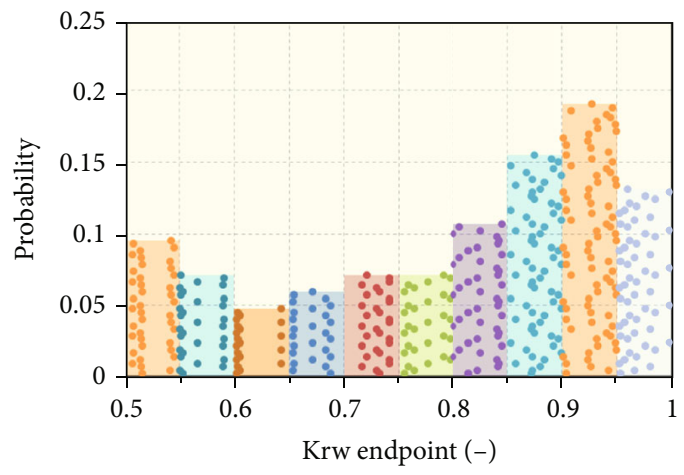

(h)

Figure 4: Continued. 


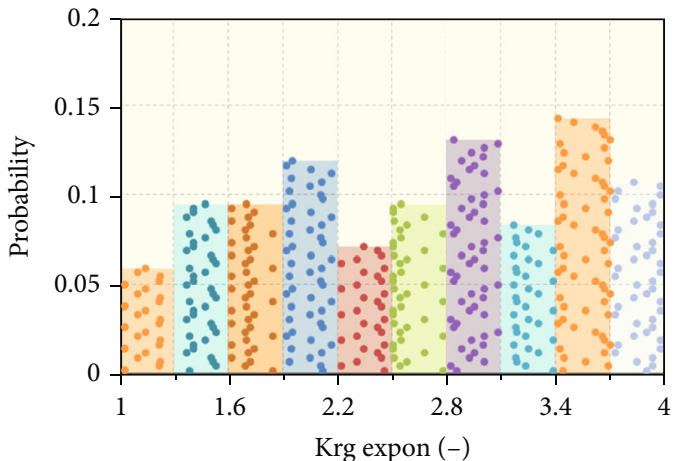

(i)

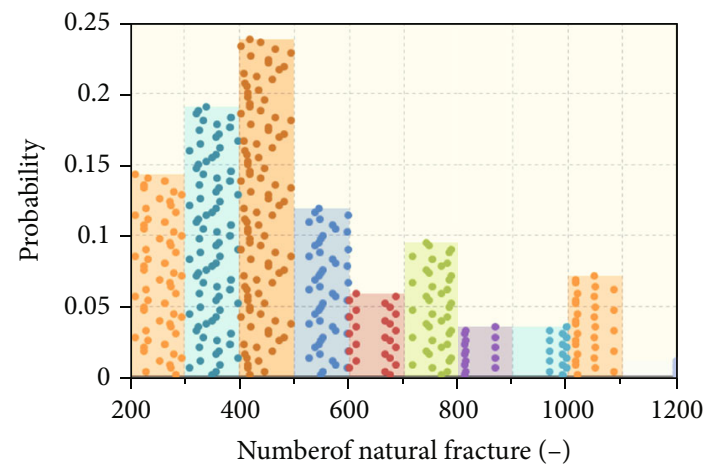

(k)

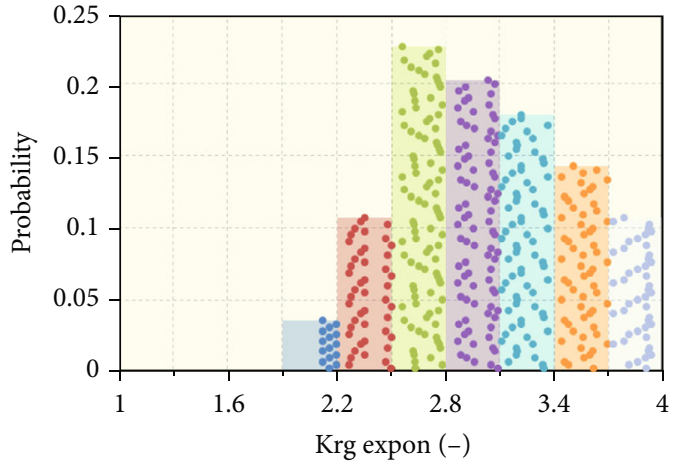

(j)

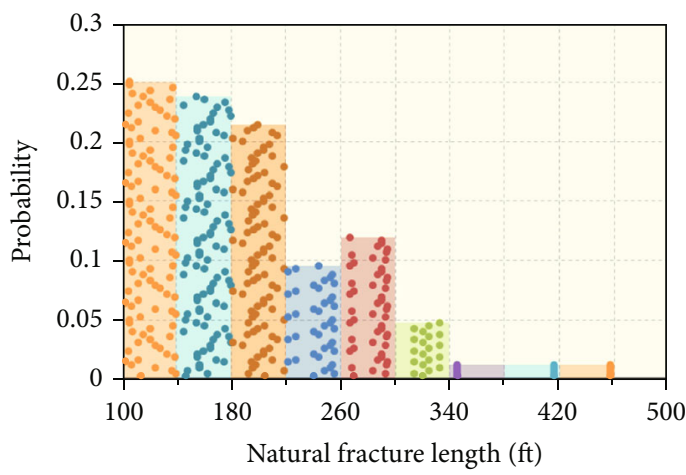

(1)

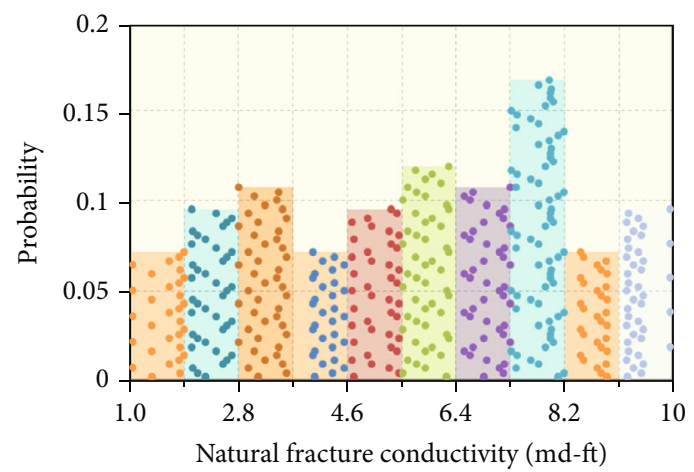

(m)

FIGURE 4: Histogram of posterior vs. prior distributions of 13 uncertain parameters: (a) matrix permeability, (b) fracture height, (c) fracture half-length, (d) fracture water saturation, (e) fracture width, (f) fracture conductivity, (g) matrix porosity, (h) the endpoint of water relative permeability, (i) the exponent of gas relative permeability, (j) the exponent of water relative permeability, (k) number of natural fracture, (l) natural fracture length, and $(\mathrm{m})$ natural fracture conductivity.

fracture height, fracture half-length, fracture water saturation, fracture width, fracture conductivity, matrix porosity, three components of relative permeability, number of natural fractures, nature fracture length, and nature fracture conductivity, respectively. Each plot's $x$-axis reflects the range of this uncertain parameter, and the range is divided into ten bins. The $y$-axis is the probability of each bin. We combined the AHM solutions with well spacing scenarios, which would generate 420 cases. One dot represents one possible case. It can be easily observed the highest probability of uncertain parameters with most points in a specific bin. The distribution of natural fracture number is shown in Figure $4(\mathrm{k})$, which implies that more than half of the points distribute between 200 and 500. Moreover, the bin of 400 to 500 has most points compared with other bins. Therefore, the possible value of the number of natural fractures would be 200 to 500, especially in the range of 400 to 500 . Similarly, we can find that the possible natural fracture length is about $100 \mathrm{ft}$ to $140 \mathrm{ft}$, and the possible natural fracture conductivity is $6.8 \mathrm{md}-\mathrm{ft}$ to $7.2 \mathrm{md}$-ft. Compared with hydraulic fracture half-length, concentrating on $316 \mathrm{ft}$ to $374 \mathrm{ft}$, the natural fractures are much shorter. And the hydraulic fracture conductivity is about $67 \mathrm{md}-\mathrm{ft}$ to $105 \mathrm{md}-\mathrm{ft}$, which is larger than that of natural fractures. It indicates that hydraulic fractures would contribute more to gas production than natural fractures. 


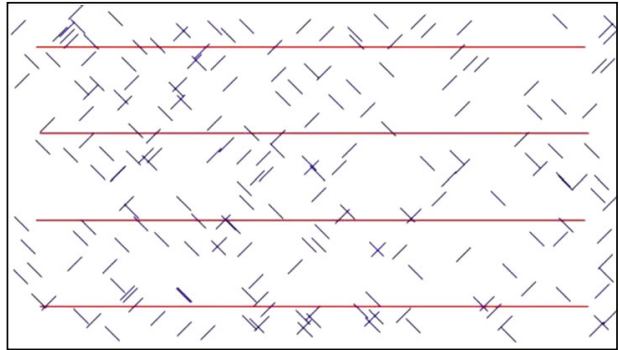

(a)

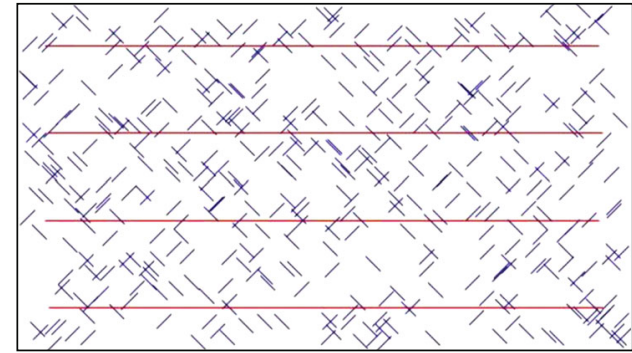

(b)

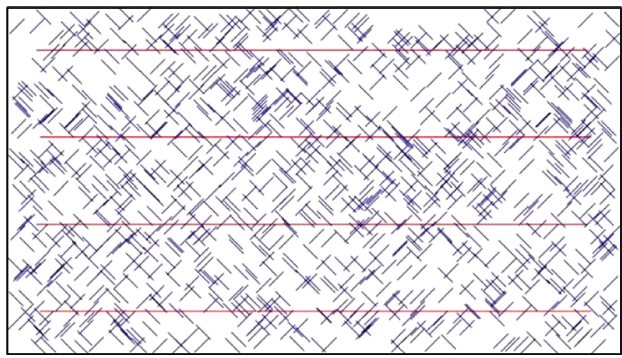

(c)

FIGURE 5: Different numbers of natural fractures under the constant length considered in the well spacing optimization: (a) minimal number, (b) P50 number, and (c) maximum number.



(a)

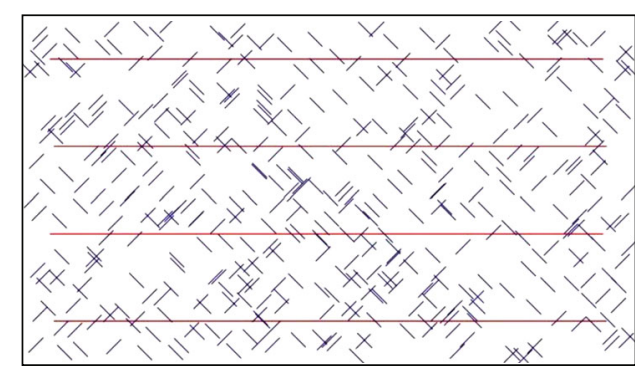

(b)

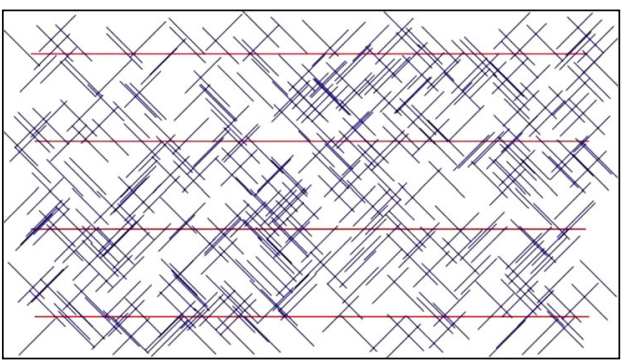

(c)

FIGURE 6: Different lengths of natural fractures under the constant number considered in the well spacing optimization: (a) minimal length, (b) P50 length, and (c) maximum length.

The probability distribution of other uncertainties can be analyzed in the same way.

To have an intuitive embodiment of natural fractures' properties, we built the fracture model using EDFM for different natural fracture numbers and lengths. Figure 5 illustrates the minimal, average, and maximum number of natural fractures: 211, 453, and 1196. All other properties are the same. Moreover, Figure 6 shows minimal, average, and maximum length of natural fractures: $102 \mathrm{ft}$, $1855 \mathrm{ft}$, and $456 \mathrm{ft}$. The more and the longer natural frac- tures, the better communication through the fracture system.

In addition, we need to consider the relative permeability of different realizations. The relative permeability of water and gas can be obtained using the following equations:

$$
\begin{aligned}
& K_{\mathrm{rw}}=K_{\mathrm{rw}}^{o} S_{\mathrm{wn}}^{N_{W}}, \\
& K_{\mathrm{rg}}=\left(1-S_{\mathrm{wn}}\right)^{N_{g},}
\end{aligned}
$$






FIGURE 7: Relative permeability curves versus water saturation of 84 history matching solutions.

where $K_{\mathrm{rw}}$ is the water relative permeability, and $K_{\mathrm{rg}}$ is the gas relative permeability. $K_{\mathrm{rw}}^{o}$ is the endpoint of water relative permeability, $N_{w}$ is the water exponent, and $N_{g}$ is the gas exponent.

$$
S_{\mathrm{wn}}=\frac{S_{w}-S_{\mathrm{wir}}}{1-S_{\mathrm{wir}}-S_{\mathrm{grw}}}
$$

where $S_{\mathrm{wn}}$ is the normalized water saturation, $S_{w}$ is water saturation, $S_{\text {wir }}$ is irreducible or residual saturation of water, and $S_{\text {grw }}$ is residual saturation of gas for a water/gas displacement.

The distribution of endpoint of water relative permeability and the exponent of relative permeability to gas and water is reflected in Figures $5(\mathrm{~h})-5(\mathrm{j})$. The relative permeability curves related to water saturation of 84 solutions are plotted in Figure 7. Red solid lines represent gas relative permeability, and blue lines represent water relative permeability. It is reflected that water relative permeability distributes wider than that of gas, which is corresponding with the greater number of uncertain parameters used in the calculation equations.

After history matching, we captured the pressure distribution in 2 years based on the 690-day production data. The initial pressure is $8000 \mathrm{psi}$ used in the reservoir simulation. It drops to 1000 psi dramatically in 2 years. Then, the pressure remains constant at $1000 \mathrm{psi}$ in the following 18 years. It implies that most gas will be produced in the first five years, especially in the first two years. It is also worth pointing out that the pressure drawdown rate decreases slightly after 100 days compared to that within 100 days.

3.2. Production Analysis. After preparing the reservoir model, we generated the 420 input cases by integrating the 84 history matching solutions with five well spacing scenarios. Then, we performed reservoir simulation for the long-term production simulation of all cases.

Firstly, the gas flow rate and water flow rate change of all cases in 20 years can be obtained, as shown in Figure 8. Different cases of the same well spacing scenario were plotted with the same color. During the production, the gas flow rate

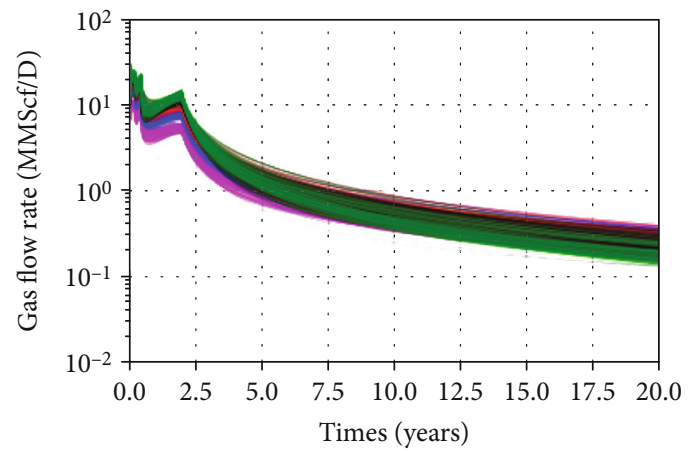

(a)

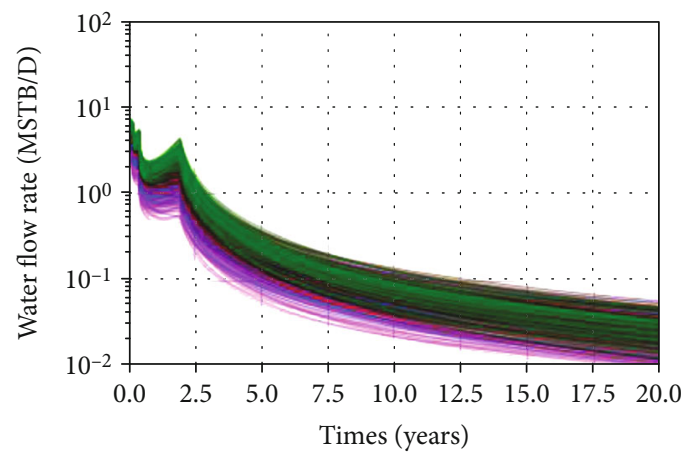

(b)

Figure 8: Gas and water flow rates for different well scenarios: (a) gas flow rate and (b) water flow rate (MMscf represents million standard cubic feet while MSTB is thousand standard barrels).



FIGURE 9: Bottomhole pressure change as the simulation constraint for all cases.

decreases first due to the pressure drop. Then, it increases a bit. It is because the pressure decrease becomes slower than the beginning, shown in Figure 9. It would lead to a larger pressure difference between the reservoir and the wellbore. Therefore, more gas and water would be produced. If the pressure drawdown rate did not change, the flow rate would decrease continuously. After two years, the gas flow rate reaches a peak and turns to decrease, which means the bottomhole pressure drops to the target pressure of 


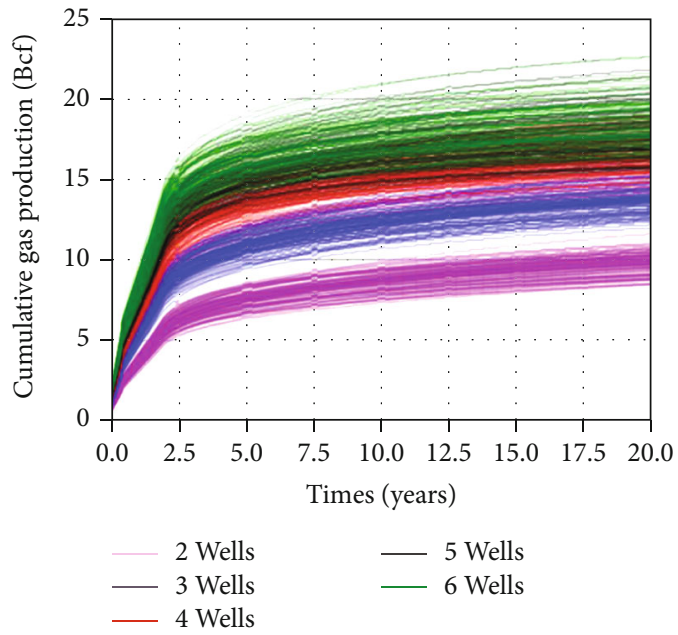

(a)
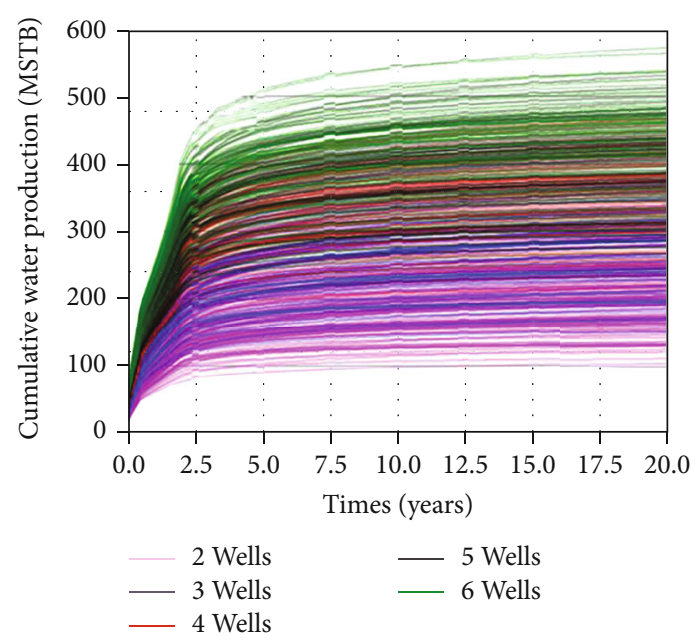

(b)

Figure 10: Cumulative gas and water productions for different well scenarios: (a) cumulative gas production and (b) cumulative water production (Bcf represents billion cubic feet).

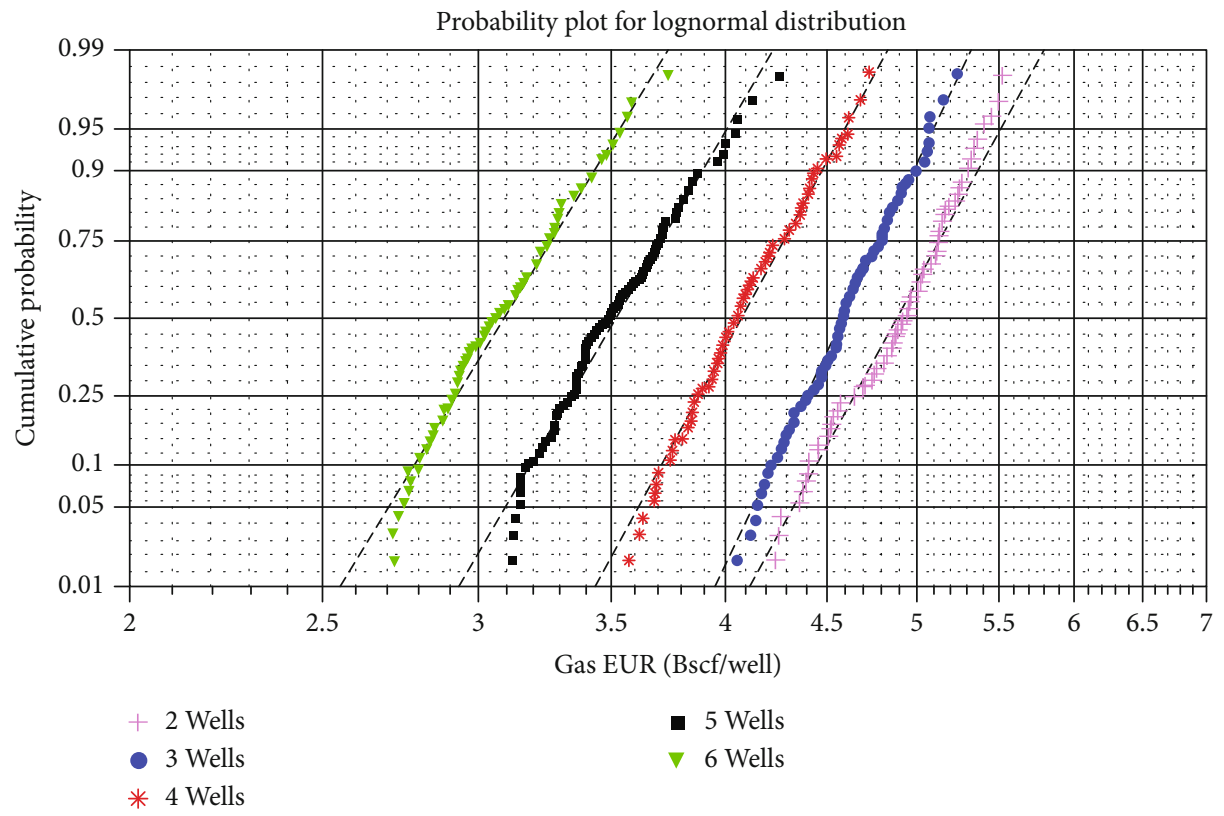

FIGURE 11: Gas estimated ultimate recovery per well for different scenarios: (a) two-well with spacing of $1550 \mathrm{ft}$, (b) three-well with spacing of $1033 \mathrm{ft}$, (c) four-well with spacing of $775 \mathrm{ft}$, (d) five-well with spacing of $620 \mathrm{ft}$, and (e) six-well with spacing of $517 \mathrm{ft}$.

1000 psi. The water flow rate has the same trend. This is the result of the pressure change. Moreover, it is observed that the six-well scenario with well spacing of $517 \mathrm{ft}$ has the largest gas flow rate and water flow rate at the beginning. The gas flow rate drops to 0.2 MMscf per day averagely for the sixwell scenario, which is the lowest among all scenarios. It implies the existence of well interference for the small well spacing.

The cumulative gas production and cumulative water production in 20 years can be obtained and plotted in Figure 10. The cumulative gas production increases dramatically in the first two years. Finally, the cumulative gas pro- duction is in the range of 10 billion cubic feet (Bcf) to $20 \mathrm{Bcf}$. The cumulative water production increases from 200 MSTB to 400 MSTB averagely with the well number increases. In addition, cumulative gas production is more concentrating than cumulative water production. It reflects the uncertainty of water and gas relative permeability.

To figure out how well spacing influences gas production, gas EUR per well for each well spacing scenario is calculated and plotted in the lognormal cumulative probability plot, as shown in Figure 11. The $y$-axis is the lognormal cumulative probability, and the $x$-axis shows the gas EUR per well. Five well spacing scenarios are represented in different colors. 
TABle 3: P10, P50, and P90 of gas EUR of five different well spacing scenarios.

\begin{tabular}{lc}
\hline Well spacing scenario & Gas EUR P50 (Bscf/well) \\
\hline 2 wells, $1550 \mathrm{ft}$ apart & 4.94 \\
3 wells, $1033 \mathrm{ft}$ apart & 4.60 \\
4 wells, $775 \mathrm{ft}$ apart & 4.05 \\
5 wells, $620 \mathrm{ft}$ apart & 3.49 \\
6 wells, $517 \mathrm{ft}$ apart & 3.07 \\
\hline
\end{tabular}

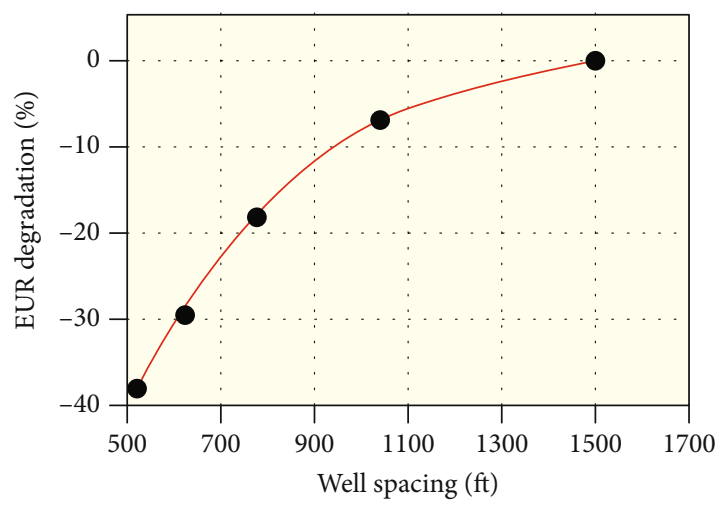

FIGURE 12: Gas EUR degradation of P50 with varying well spacing.

More dots falling on the corresponding dashed fitting line indicate a higher possibility of the gas EUR distributes in the lognormal format. What is more, the larger the well spacing, the larger the gas EUR per well. We can find the P50 gas EUR for each scenario, listed in Table 3.

Then, the P50 gas EUR degradation related to well spacing is calculated and plotted in Figure 12. It implies that when the well spacing is smaller than $775 \mathrm{ft}$, the gas EUR degrades significantly up to $37 \%$. This means there is a strong well interference under this well spacing. Then, the well interference becomes smaller and smaller when then well spacing increases from $775 \mathrm{ft}$ to $1033 \mathrm{ft}$. When the well spacing is larger than $1033 \mathrm{ft}$, the degradation curve changes is little, which means the well interference could be ignored. Therefore, we need to make sure the well spacing is larger than $775 \mathrm{ft}$ to reduce the influence of well interference.

3.3. Well Spacing Optimization. Next, we calculated the net present value (NPV) to determine the optimal well spacing. The values of NPV calculation inputs are listed in Table 4 . The operation cost is 4.5 million USD per well, and the gas price is $1.8 \mathrm{USD} / \mathrm{MScf}$. Other values can be seen in the table.

The result of NPV is plotted in the boxplot, as shown in Figure 13. The $x$-axis represents the NPV while the $y$-axis represents the well spacing. The NPV result of each scenario is drawn in one box. The three lines of the box from higher to lower are the P25, P50, and P75 NPV of each scenario. The highest line outside the box means the maximum NPV, and the lowest line outside the box represents the minimum NPV. There exists a maximum NPV along with the well spacing. Therefore, the optimum well spacing is $775 \mathrm{ft}$ at
TABLE 4: Summary of economic input variables used in this study.

\begin{tabular}{lcc}
\hline NPV calculation inputs & Value & Unit \\
\hline Well cost & 4.5 & Million USD/well \\
Gas price & 1.8 & USD/MScf \\
Water disposal cost & 1.35 & USD/bbl \\
Gas tax rate & 9.0 & $\%$ \\
Other tax rates & 5.00 & $\%$ \\
Annual discount rate & 15 & $\%$ \\
Total simulation time & 20 & Year \\
\hline
\end{tabular}

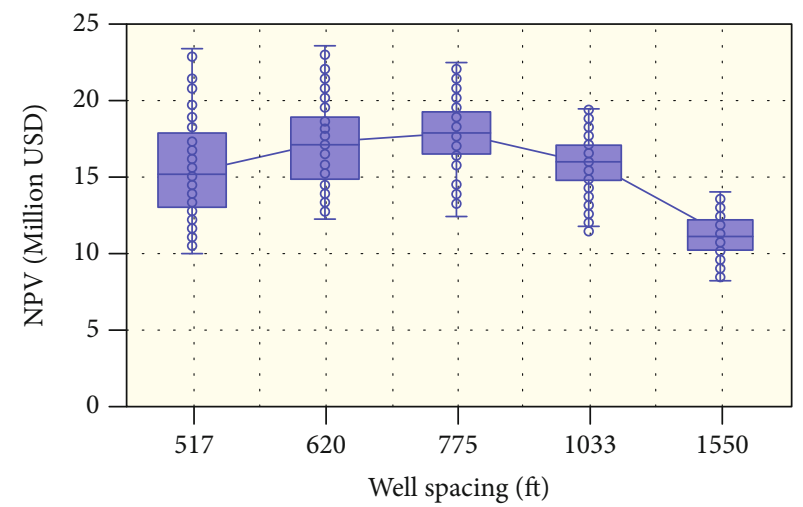

FIGURE 13: Economic uncertainty distribution with different well spacing scenarios.

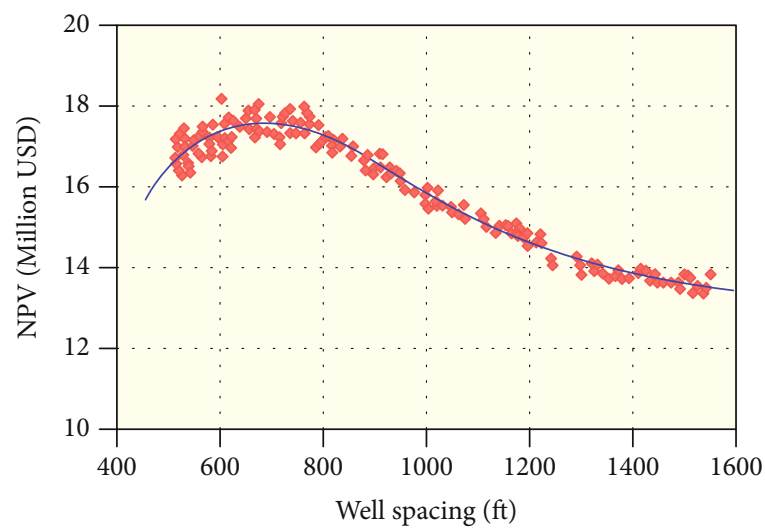

FIGURE 14: Interpolated relationship between NPV and well spacing.

where the NPV reaches the highest. The highest P50 NPV is about 18 million USD.

Then, we applied the KNN proxy model to train the data and predict the NPV relationship with well spacing. Each point in Figure 14 represents one prediction result and is regressed on one polynomial curve, shown as a blue line. It is observed that the optimal well spacing is $793 \mathrm{ft}$ with 18 million USD. Also, this well spacing can satisfy the requirement of critical well spacing. It is worth pointing out that this result is similar to the boxplot result, but this curve is smoother with more points. Therefore, the KNN proxy method could 


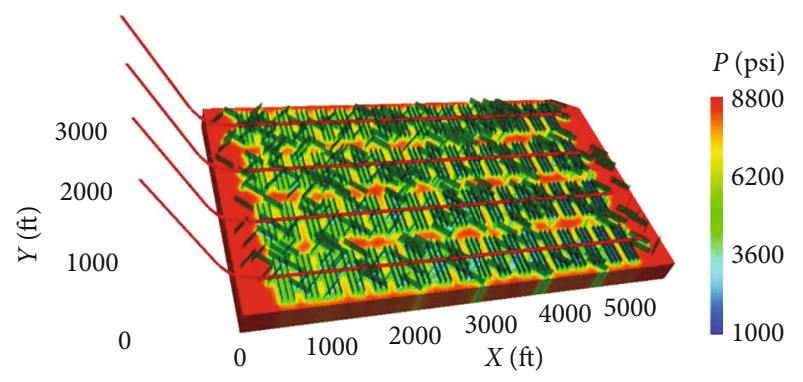

(a)



(b)

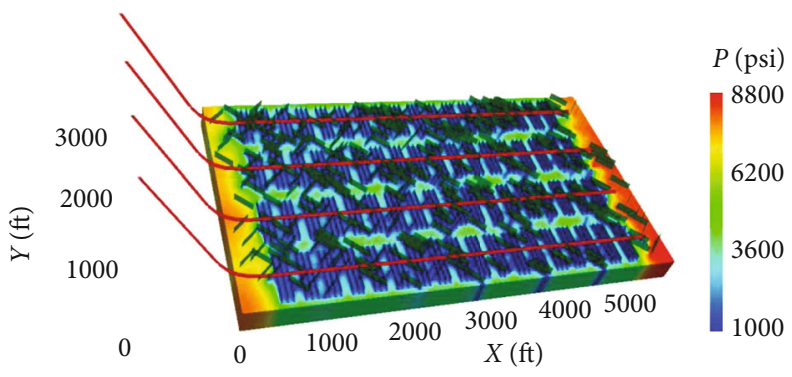

(c)

FIGURE 15: Pressure distributions in the matrix for the optimal well spacing scenario: (a) after 1 year, (b) after 5 years, and (c) after 20 years.

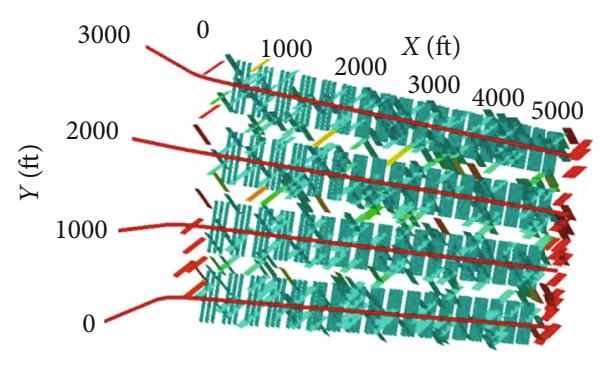

(a)
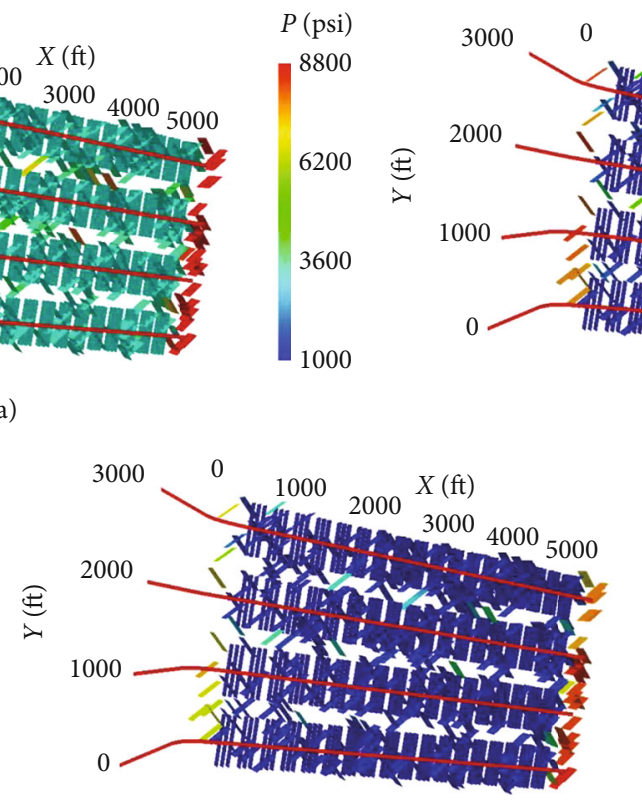
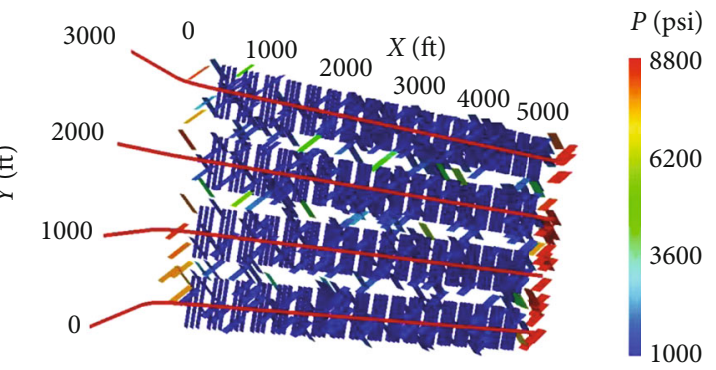

(b)

(c)

FIGURE 16: Pressure distributions in the fractures for the optimal well spacing scenario: (a) after 1 year, (b) after 5 years, and (c) after 20 years.

provide a more reliable result for the optimum well spacing decision.

3.4. Pressure Distribution Visualization. Finally, we combined the optimal well spacing of $793 \mathrm{ft}$ with the lowest global error AHM solution to perform the reservoir simulation and predict the pressure distribution in the long time. The matrix permeability is $202 \mathrm{Nd}$, and porosity is 0.04 . The water exponent, the gas exponent, and the endpoint of relative water permeability are $2.46,3.91$, and 0.55 , respectively. Fracture height, fracture half-length, fracture conductivity, fracture water saturation, and fracture width are $44 \mathrm{ft}, 289 \mathrm{ft}$, $194 \mathrm{md}-\mathrm{ft}, 0.82$, and $0.5 \mathrm{ft}$, respectively. The number of natural fractures is 418 , and its length is $270 \mathrm{ft}$ with a conductivity of 8.09 md-ft. Next, we modeled the fractures by EDFM. After the reservoir simulation, the pressure distribution in the matrix is shown in Figure 15. The pressure drops significantly in the first five years, which implies that most gas would be produced in the first 5 years. However, we would like to perform long-term EUR prediction. Therefore, we 


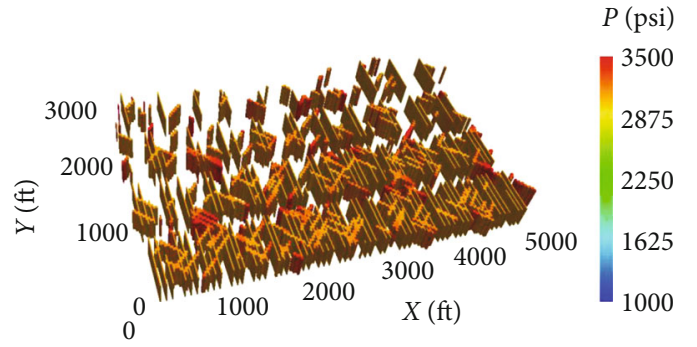

(a)



(b)

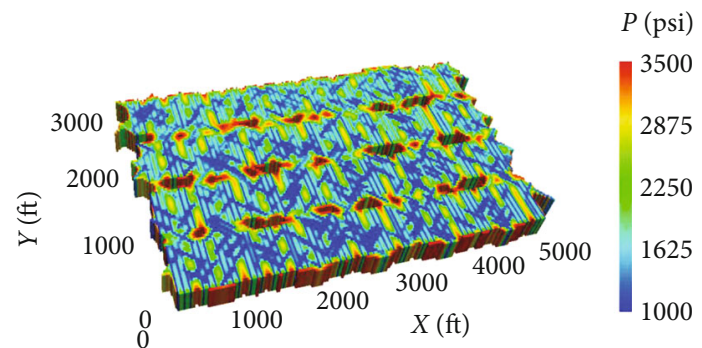

(c)

FIGURE 17: Drainage volume for the optimal well spacing scenario: (a) after 1 year, (b) after 5 years, and (c) after 20 years.

would predict the 20-year production in this study. Figure 16. shows the pressure distributions in the fracture. We can find that the pressure drop is faster of the hydraulic fractures than natural fractures far away from the well. It drops from 8000 psi to 3000 psi. This implies that hydraulic fractures would play a more critical role in the gas production process in the early time. In addition, the hydraulic fracture pressure drops to low pressure in the first five years. And the pressure of the natural fractures far from the wellbores drops more than that of hydraulic fracture after five years, which implies natural fractures contribute more after five years. The drainage volume is illustrated intuitively in Figure 17, clearly showing the strong well interference after five years of production.

\section{Conclusions}

This study applied the well spacing optimization workflow for shale gas reservoirs with hydraulic and complex natural fractures in the Sichuan Basin by integrating AHM and EDFM. A total of 84 AHM solutions and five well spacing scenarios were used to predict gas EUR and NPV in 20 years. Then, the optimum well spacing was identified. We summarize the following conclusions from the study:

(1) The maximum NPV is around 18 million USD, whether directly calculated or predicted by the KNN proxy model. The corresponding optimum well spacing is $775 \mathrm{ft}$ and $793 \mathrm{ft}$, respectively, for the two methods. Moreover, the optimum well spacing from KNN proxy is more accurate as considering more well spacing scenarios

(2) The gas EUR degradation reaches to $35 \%$ when the well spacing is $517 \mathrm{ft}$, which shows substantial well interference. And when the well spacing is more extensive than $775 \mathrm{ft}$, the degradation rate starts becoming slow. It indicates that the influence of well interference turns to small

(3) The critical well spacing to avoid the influence of well interference is $775 \mathrm{ft}$. Therefore, optimum well spacing obtained from the two methods is satisfied with this critical spacing

(4) The pressure drop of hydraulic fractures is faster than natural fractures, which implies that hydraulic fractures are more important for early time shale gas production. Then, for a longer time, the natural fractures contribute more to the gas production

\section{Acronyms}

AHM: Assisted history matching

BHP: Bottomhole pressure

EUR: Estimated ultimate recovery

EDFM: Embedded discrete fracture model

HM: History matching

KNN: K-nearest neighbor

LGR: Local grid refinement

NPV: Net present value.

\section{Nomenclature}

$C_{\text {fixed }}$ : Fixed well maintenance cost

$C_{i}: \quad$ Total cost of a specific month

$C_{\text {water }}$ : Water disposal cost

$C_{\text {well }}$ : Total individual well cost

$d_{\mathrm{NNC}}$ : Distance associated with this connection.

$I_{i}$ : $\quad$ Gross income of a specific month

$K_{\mathrm{NNC}}:$ Permeability 
$N_{\text {well }}: \quad$ Number of wells

$N P V_{n}$ : Net present value of a specific scenario

$P_{\text {gas }}: \quad$ Gas price (dollars per million standard cubic feet)

$q: \quad$ volume flow rate between two cells in a NNC pair

$R: \quad$ Annual discount rate

$T_{\mathrm{ex}}: \quad$ Miscellaneous tax rate

$T_{g}$ : Gas tax rate

$T_{\text {NNC: }}$ Transmissibility factors in each of NNC pair

$V_{\text {gas }, i}:$ Gas production in a specific month (million standard cubic feet)

$V_{\text {water } i}:$ Water production in a specific month (barrels)

$\lambda: \quad$ Relative mobility.

\section{SI Metric Conversion Factors}

$\mathrm{ft} \times 3.048 e-01=\mathrm{m}:$

$\mathrm{ft}^{3} \times 2.832 e-02=\mathrm{m}^{3}$ :

psi $\times 6.895 e+00=\mathrm{kPa}:$

$\mathrm{md} \times 1 \mathrm{e}-15 e+00=\mathrm{m}^{2}$ :

\section{Unit Abbreviation Table}

Bcf: Billion standard cubic feet

MMscf: Million standard cubic feet

MSTB: Thousand stock tank barrel

md: $\quad$ Millidarcy

nd: Nanodarcy.

\section{Data Availability}

Data are available upon request.

\section{Additional Points}

Highlights. (1) Optimum well spacing for shale gas reservoirs was obtained. (2) Both the influences of natural fractures and hydraulic fractures were considered. (3) AHM calibrated thirteen uncertainty parameters of fractures and matrix. (4) EDFM was performed to establish fracture models. (5) Maximum NPV predicted from the KNN model determined the optimum well spacing.

\section{Conflicts of Interest}

The authors declare that they have no conflicts of interest.

\section{Acknowledgments}

The authors would like to acknowledge Sim Tech LLC for providing EDFM software for this study.

\section{References}

[1] Y. Gong, M. Mehana, I. El-Monier, and H. Viswanathan, "Proppant placement in complex fracture geometries: a computational fluid dynamics study," Journal of Natural Gas Science \& Engineering, vol. 79, p. 103295, 2020.

[2] K. Sepehrnoori, Y. Xu, and W. Yu, Embedded Discrete Fracture Modeling and Application in Reservoir Simulation, Elsevier, Cambridge, USA, 1st edition, 2020.
[3] J. Xu, Z. Chen, and R. Li, "Impacts of pore size distribution on gas injection in intraformational water zones in oil sands reservoirs," Oil \& Gas Science and Technology - Revue d'IFP Energies Nouvelles, vol. 75, no. 6, p. 75, 2020.

[4] H. O. Balan, A. Gupta, D. T. Georgi, and A. M. Al-Shawaf, "Optimization of well and hydraulic fracture spacing for tight/shale gas reservoirs," in Paper URTEC 2435369, presented at Unconventional Resources Technology Conference, San Antonio, Texas, USA, August 2016.

[5] H. Zhang and J. Sheng, "Optimization of horizontal well fracturing in shale gas reservoir based on stimulated reservoir volume," Journal of Petroleum Science and Engineering, vol. 190, p. 107059, 2020.

[6] F. Alimahomed, E. Wigger, M. Drouillard, G. G. Rosas, and C. Kolbeck, "Impact of pore pressure on modeled hydraulic fracture geometry and well spacing in the East Duvernay Shale Basin, Canada," in Proceedings of the 7th Unconventional Resources Technology Conference, Denver, Colorado, July 2019.

[7] Z. Lei, K. Dai, X. Dou et al., "Optimization well spacing for development of shale oil reservoirs using integration of data analytics, geomechanics modeling, pilots, and economic analysis," in Paper URTEC 2020-3197, presented at Unconventional Resources Technology Conference, Virtual, July 2020.

[8] V. Sahai, G. Jackson, R. Rai, and L. Coble, "Optimal well spacing configurations for unconventional gas reservoirs," in Paper SPE 155751, presented at the SPE Americas Unconventional Resources Conference, Pittsburgh, Pennsylvania, June 2012.

[9] R. Cao, R. Li, A. Girardi, N. Chowdhury, and C. Chen, "Well interference and optimum well spacing for Wolfcamp development at Permian Basin," in Paper URTEC 2691962, presented at SPE/AAPG/SEG unconventional resources technology conference, Austin, Texas, July 2017.

[10] A. Iino, T. Onishi, F. Olalotiti-Lawal, and A. Datta-Gupta, "Rapid field-scale well spacing optimization in tight and shale oil reservoirs using fast marching method," in Paper URTEC 2901376, presented at SPE/AAPG/SEG Unconventional Resources Technology Conference, Houston, TX, July 2018.

[11] V. Grechka, Z. Li, B. Howell, H. Garcia, and T. Wooltorton, "Microseismic imaging of unconventional reservoirs," in Paper SEG 2018-2995627, presented at SEG International Exposition and Annual Meeting, Anaheim, California, October 2018.

[12] B. Liang, M. Du, C. Goloway, R. Hammond, P. P. Yanez, and T. Tran, "Subsurface well spacing optimization in the Permian Basin," in Paper URTEC 2671346, presented at SPE/AAPG/ SEG Unconventional Resources Technology Conference, Austin, Texas, July 2017.

[13] Y. Wang and X. Yi, "Flow modeling of well test analysis for a multiple-fractured horizontal well in triple media carbonate reservoir," International Journal of Nonlinear Sciences and Numerical Simulation, vol. 19, no. 5, pp. 439-457, 2018.

[14] W. Wang, K. Zhang, Y. Su, M. Tang, Q. Zhang, and G. Sheng, "Fracture network mapping using integrated micro-seismic events inverse with rate-transient analysis," in Paper IPTC 19445, presented at International Petroleum Technology Conference, Beijing, China, March 2019.

[15] N. Bansal, J. Han, Y. Shin, and T. Blasingame, "Reservoir characterization to understand optimal well spacing \&ndash; a wolfcamp case study," in Paper URTEC 2901322, presented at SPE/AAPG/SEG Unconventional Resources Technology Conference, Houston, Texas, July 2018. 
[16] H. Belyadi and M. Smith, "A fast-paced workflow for well spacing and completions design optimization in unconventional reservoirs," in Paper SPE 191779, presented at SPE/AAPG Eastern Regional Meeting, Pittsburgh, Pennsylvania, October 2018.

[17] N. Li, E. Lolon, M. Mayerhofer, Y. Cordts, R. White, and A. Childers, "Optimizing well spacing and well performance in the Piceance Basin Niobrara Formation," in Paper SPE 184848, presented at SPE Hydraulic Fracturing Technology Conference and Exhibition, the Woodlands, Texas, January 2017.

[18] M. Rafiee and T. Grover, "Well spacing optimization in eagle ford shale: an operator's experience," in Paper URTEC 2695433, presented at SPE/AAPG/SEG Unconventional Resources Technology Conference, Austin, Texas, July 2017.

[19] J. Zhu, J. Forrest, H. Xiong, and A. Kianinejad, "Cluster spacing and well spacing optimization using multi-well simulation for the lower Spraberry Shale in Midland Basin," in Paper SPE 187485, presented at SPE Liquids-Rich Basins ConferenceNorth America, Midland, Texas, September 2017.

[20] R. Cao, C. Chen, R. Li et al., "Integrated stochastic workflow for optimum well spacing with data analytics, pilots, geomechanical-Reservoir modeling, and economic analysis," in Paper URTEC 2902138, presented at SPE/AAPG/SEG Unconventional Resources Technology Conference, Houston, Texas, July 2018.

[21] M. K. Fisher and N. R. Warpinski, "Hydraulic-fracture-height growth: real data," SPE Production \& Operations, vol. 27, no. 1, pp. 8-19, 2012.

[22] K. Wu and J. E. Olson, "Simultaneous multifracture treatments: fully coupled fluid flow and fracture mechanics for horizontal wells," SPE Journal, vol. 20, no. 2, pp. 337-346, 2015.

[23] K. Wu and J. E. Olson, "Numerical Investigation of Complex Fracture Networks in Naturally Fractured Reservoirs," SPE Production \& Operation, vol. 31, no. 4, pp. 337-346, 2016.

[24] S. Agrawal, K. Shrivastava, and M. Sharma, "Effect of shear slippage on the interaction of hydraulic fractures with natural fractures," in Paper SPE 194361, presented at the SPE Hydraulic Fracturing Technology Conference and Exhibition, The Woodlands, Texas, February 2019.

[25] C. Liu, W. Yu, C. Chang, Q. Li, and K. Sepehrnoori, "Proxy based assisted history matching and well spacing optimization in shale gas development of a real field case," in Paper SPE 200466, presented at SPE Improved Oil Recovery Conference, Virtual, August 2020.

[26] S. Tripoppoom, X. Ma, R. Yong et al., “Assisted history matching in shale gas well using multiple-proxy-based Markov chain Monte Carlo algorithm: the comparison of K-nearest neighbors and neural networks as proxy model," Fuel, vol. 262, p. $116563,2020$. 